Presented at the Particle Accelerator Conference,

Chicago, IL., March 1-3, 1971
. UCRL-20166

Preprint

CONf- $710308--3$

STTR

\title{
NON-INTERCEPTING MONITOR OF BEAM CURRENT AND POSITION
}

Robert $T$. Avery, Andris Faltens and Edward C. Hartwig

February 1971

AEC Contract No. W -7405-eng-48
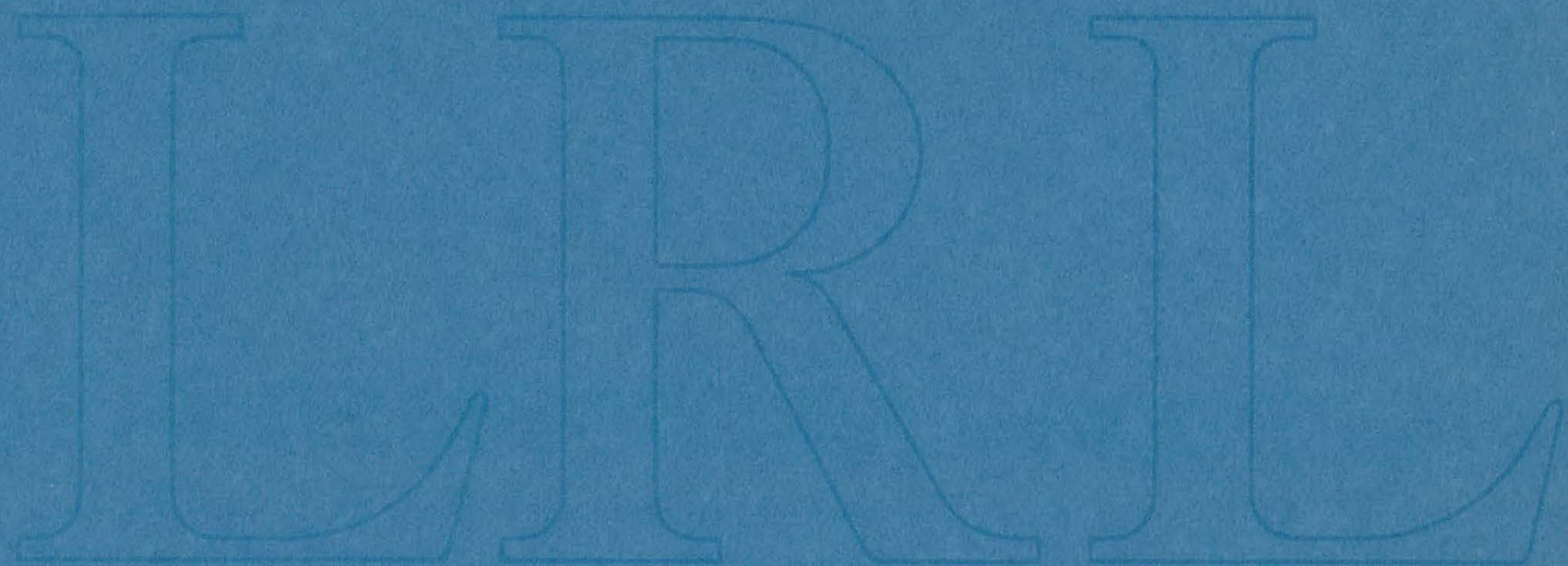

LAWRENCE RADIATION LABORATORY UNIVERSITY of CALIFORNIA BERKELEY 


\section{DISCLAIMER}

This report was prepared as an account of work sponsored by an agency of the United States Government. Neither the United States Government nor any agency Thereof, nor any of their employees, makes any warranty, express or implied, or assumes any legal liability or responsibility for the accuracy, completeness, or usefulness of any information, apparatus, product, or process disclosed, or represents that its use would not infringe privately owned rights. Reference herein to any specific commercial product, process, or service by trade name, trademark, manufacturer, or otherwise does not necessarily constitute or imply its endorsement, recommendation, or favoring by the United States Government or any agency thereof. The views and opinions of authors expressed herein do not necessarily state or reflect those of the United States Government or any agency thereof. 


\section{DISCLAIMER}

Portions of this document may be illegible in electronic image products. Images are produced from the best available original document. 

nmission, nor any of their employees, nor anyes, ir contractors, subcontractors, or their emplied, or assumes any kes any warranty, expribility for the accuracy, comor usefulness of any information, apparatus, or process disclosed, or represents that its use infringe privately owned rights.

\title{
NON-INTTERCEPTING MONITOR OF BEAM CURRENT AND POSTITION*
}

Robert T. Avery, Andris Faltens and Edward C. Havtwig

\author{
Lawrence Radiation Laboratory \\ University of California \\ Berkeley, Callfornla
}

\section{Summary}

A compact monitor has been developed which measures beam current and beam position without intercepting or appreclably affecting the particle beam being measured. It is a broad band device which prevents the development of beam disturbing resonant modes. Although developed specifically for use on a short-pulse electron induction accelerator, it might be applied to other accelerator beams of pulsed or rf-bunched nature. The monitor consists of a resistive band inserted in the beam pipe wall with connections for reading the voltage across the band at each vertical and horizontal axis intercept. For pulsed or rf beams, return current equal in magnitude to the beam current 1 lows on the beam pipe inside wall and through the resistive band. If the beam is centered, equal voltage appears on all four monitor connections. If the beam is off-center, the return currents are unsymmetrical and unequal voltages appear at the monitor connections. Beam current is proportional to the sum of all monitor voltages, while beam position is approximately proportional to the difference in voltage at opposing monitors. Tests and operating experience confirm 1ts operation.

\section{Principle of Operation}

Following is a somewhat simplified analysis which illustrates the principles. Consider a beam pulse of charged particles moving through a beam pipe (Fig. 1). For relativistic beams $(\gamma>2)$ this is analogous to a pulse traveling along a coaxial transmission line. The beam current induces currents of opposite polarity in the woll. These wall currents have approximately the same pulse shape and magnitude as the beam current. The current distribution on the wall, however, is dependent on the position and shape of the beam pulse. For an off-center line current the wall current distr1bution is $J_{z}=\frac{I}{2 \pi a} \frac{\left(r^{2}-a^{2}\right)}{\left(a^{2}+r^{2}-2 a r \cos \theta\right)}$ where $r$ is the displaccment from center, $a$ is the pipes radius, and $\theta$ 1s the angle from some reference plane to the plane between the beam and the center. The smoothing of the current wave shape at the front and rear of the pulse 1s dependent on geometric factors and beam velocity, giving a rise time of the order of $\frac{a}{\gamma c}$, which is typ1cally less than $1 \mathrm{~ns}$. The wall current magnitude remains equal to the beam current mignitude at least until the magnet1c pield of the beam starts to penetrate through the wall, typlcally $10^{-5}$ to $10^{-3} \mathrm{sec}$, after which time the magnitude will change if an alternate current return path exists outside the beam p1pe. So, for a wide range of pulse durations the wall current closely duplicates the beam current.

Next, consider the case where a short length of the wall is replaced by a section with a circumferentially uniform resistance $R_{B}$. If the beem is centered, the resulting unfform wall current produces a circumferentirlily uniform vollage drop $e=1 \mathrm{R}_{\mathrm{g}}$. If the boam io off center (Fie. 3), the wall current density is highest where the beam is closest and for small offsets $r$, the voltage drop can be expressed approximately as

* Work supported by the U.S. Atomic Energy Comm1ssion.

$$
e \approx 1 R_{s}\left[1+2 \frac{r}{a} \cos (\theta-\phi)\right]
$$

If voltage sensors are placed at the axis intercepts and noting that $\Delta x=r \cos \theta$ and $\Delta y=r \sin \theta$, we get

$$
\begin{gathered}
e_{x l}+e_{x 2}+e_{y 1}+e_{y 2}=41 R_{b} \\
e_{x l}-e_{x 2} \approx 41 R_{B} \frac{\Delta x}{a} \\
e_{y 1}-e_{y 2} \approx 41 R_{s} \frac{\Delta y}{a}
\end{gathered}
$$

These equations indicate that all are proportional to the beam current, that the sum signal is independent of beam position, and that the two difference signals are proportional to beam position in the $x$ and $y$ directions respectively. How good are the approximations? The sum of currents at four monitoring points and $\theta=0$ gives

$$
\Sigma J_{z}=\frac{I}{2 \pi} \frac{2 a+r}{a^{2}-r^{2}}+\frac{2 a^{2}-r a-2 r^{2}}{a\left(a^{2}+r^{2}\right)}
$$

which is within $5 \%$ of $\frac{I}{2 \pi} \quad \frac{4}{a}$ to $r=\frac{a}{2}$. The difference In the currents between two diagonal points is $J_{z}=\frac{I}{2 \pi} \frac{3 r}{a^{2}-r^{2}}+\frac{r}{a^{2}+r^{2}}$ which is within $5 \%$ of the approximation $\Delta J_{z}=\frac{I}{2 \pi} \frac{4 r}{a}$ to about $r=\frac{a}{4}$. In both cases the approximations improve as the beam is steered toward the center.

What might be the Iimitations of the device? First, the inftially non-uniform current (and voltage) distribution of $\mathrm{Eq}$. (1) decays to a unfform azimuthal distribution at a rate dependent on the inductance $\mathrm{L}_{\mathrm{d}}$ of the "difference current" circult, which produces magnetic field of character shown by the dashed lines in $\mathrm{FIg}$. 3, and on the portion of the resistance $\mathrm{R}_{\mathrm{g}}$ coupled by this circuit. The exact time dependence for the decay of the transverse voltages has not been worked out yet, but 1t $1 \mathrm{~s}$ clear that the transverse inductance $L_{g}$ is small, of the order of $2 \times 10^{-9} \times$ In $\frac{a^{2}}{a^{2}-x^{2}}$ Hy per cm, and that the decay is not simply exponential. For a $0.1 \Omega \mathrm{R}_{\mathrm{S}}$, the decay is shown in Fig. 6, and is sufficlently slow to be used with our $<45$ ns beams. If the $L_{d} / R_{\mathrm{g}}$ ratio is not high, the difference current mlght have a waveshape as shown in Fig. 2C. Second, if there is an external ground return c1rcult (dashed Iine in F1g. 1), the current through the resistors $R_{s}$ will gradually shift to $1 t$ at a rate dependent on the inductance $\mathrm{L}_{e}$ of the enclosed volume and the resistance of the loop circuit (primarily $R_{g}$ ) with a high $\mathrm{L}_{\mathrm{e}} / \mathrm{R}_{\mathrm{g}}$ ratio beling desirable. Ferrite or other ferromagnetic material might be used to increase the foregolng Inductances and forestall current decay (Ref. $\mu$ in Fig. 1).

\section{Selected Configuration}

Fifteen beam monitors have been fabricated and installed in the FRA 4-MeV Injector ${ }^{1}$ wich produces a pulsed electron beam of $\sim 1,000$ A for $45 \mathrm{~ns}$ at a rate of $1 \mathrm{~Hz}$. A beam chopper 1s used to shorten the pulse 
length to elther $5 \mathrm{~ns}$ or 20 ns at the output of the accelerator. The selected configuration is shown in F1gures 4 and 5.

The monitor was designed to fit on the 11.75-1nch diameter metal flanges of the accelerator beam plpe. This arrangement occuples a mintmum of beam plpe length and permits beam monitoring at any beam pipe joint by addition of an insulating sheet between flanges. The waveform distortion due to the resistors being at the outside diameter, instead of Inside diameter, 1s small $(<1 \mathrm{~ns})$. The shunt reslstance $R_{\mathrm{B}}$ cons1sts of 100 onewatt carbon resistors in parallel, each having a resistance of $10 \Omega$ for a total resistance $R_{\mathrm{g}}=0.1 \Omega$. This value was chosen because it would give a large enough signal to be used with a Tektronix 519 scope. This gives a voltage level of $100 \mathrm{~V}$ for $1000 \mathrm{~A}$ beam current. The inductance of the 100 parallel resistors 1s of the order of $10^{-10} \mathrm{H}$ wh1ch produces only $\sim 100 \mathrm{~V}$ for a current rise of $1000 \mathrm{~A}$ per nanosecond. For our pulse lengths signs.l decay as described at the end of the preceding section is not a problem. The resistors are soldered to two split copper rings which are easily clamped to the beam pipe flanges.

Two coaxial connections are made to the resistor assembly at each $90^{\circ}$ station ( 8 total). A 50 \& backterminating resistor is used at each connection. Four coaxial lines, one from each quadrant, are fed together to give the "sum" signal proportional to beem current. Two coaxial lines at $180^{\circ}$ intervals are combined, with inversion of one, to give the $\Delta x$ or $\Delta y$ "difference" signala proportional to beam position.

\section{Calibration}

The beam monitor was bench calibrated using a short length of coaxial line. The outer conductor was of $11.75^{\prime \prime}$ diameter to simulate the beam pipe. A radlally movable inner conductor of $1 / 2^{\prime \prime}$ diameter was used. to simulate the electron beam. A pulse enemtor supplied pulses of I ns rise. Flgure 6 shows waveforms of the "sum" and "difference" $\mathrm{s} 1 \mathrm{gnals}$ for $2 \mathrm{~cm}$ displacement steps. It was found that the difference signal was closely proportional to the center conductor radial position, with the linearity evident from the evennes: of the oscilloscope traces. The amplitudes of the sum and difference oignals were approximately equal for $r=a$, thus a convenient calibration 1 s $\frac{r}{a}=\frac{\Delta I}{\Sigma I}$.

\section{Performance on Accelerator}

The beam monftors bave been used successfully on the ERA 4-MeV Injector to measure both current and position. Typical waveforms are shown in Figure 7 . Values of current agree well w1th independent measurements by toroldal transformer and Faraday cup techn1ques. Beam position data agrees qualitatively with beam movement on scintillation Bcreens and with beam yleering characteristics. The primary funntion of the position monitors is to help in centering the beam in the beam p1pe. This is the region where the approximations made about a linear output versus position are most accurate.

\section{Future Possibilities}

In our present configuration (Ref. Section 3), the monitoring resistors are exposed. In some situations th1s could pose a problem with radio-frequency interference, although we have not observed any problem here. If 1t should be a problem, the resistors could be enclosed in a moderate-sized housing (dashed lines of Fig. 1), possibly including ferromagnetic material. our arrangement with 100 resistors provides response of a nanosecond or so. If faster response is desired, one could consider an azimuthally uniform resistive band of, for example, some highly resistive material (e.g. carbon) or an evaporated metal coating. The time decay of the beam position signal can most easily be Improved by lowering the value of the resistance of the band.

\section{Conclusions}

Clearly, the shunt may be used to measure currents in any coaxial system, whether the inner current is electrons in vacuum or in copper. The use of the monltor on a beam pipe has the benefits of not constricting the aperture or putting a large discontinuity in the beam pipe. The device is located outside of the vacuum area and is readily accessible.

\section{References}

1. W. Chupp, et.21., The ERA $4 \mathrm{MeV}$ Injector, 1971 Particle Accelerator Conference, paper G-9.
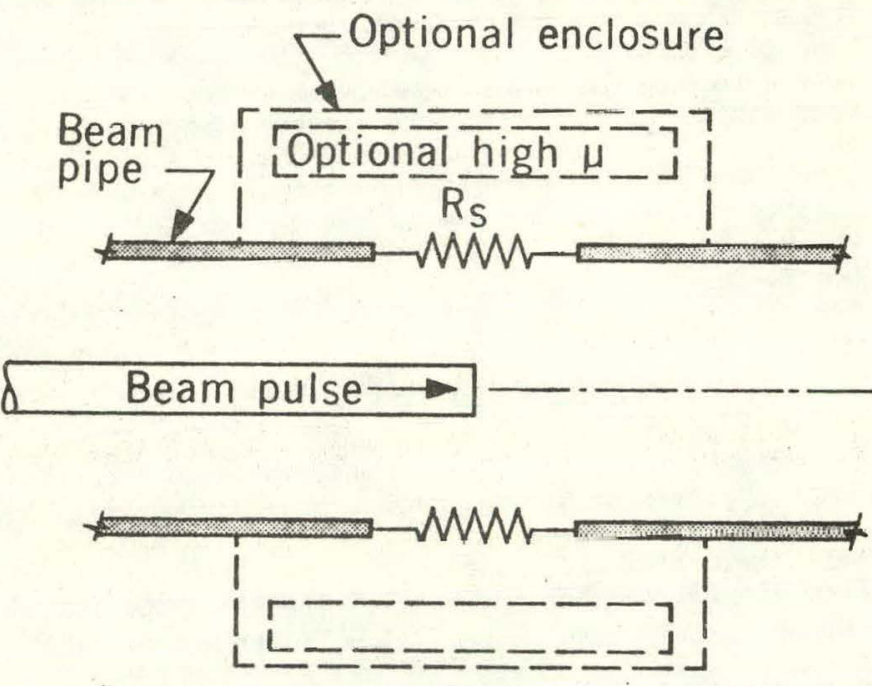

Figure 1 - Conceptual diagram showing beam pulse traversing monitor ring of resistance $R_{s}$.

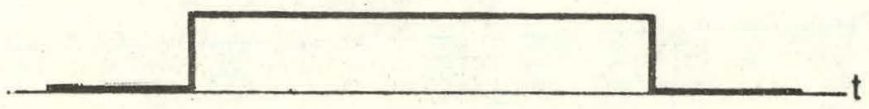

a) Beam current

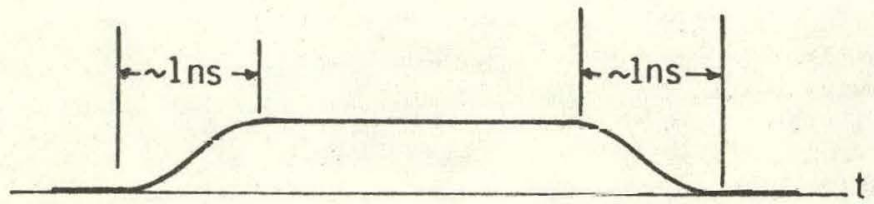

b) Monitor current

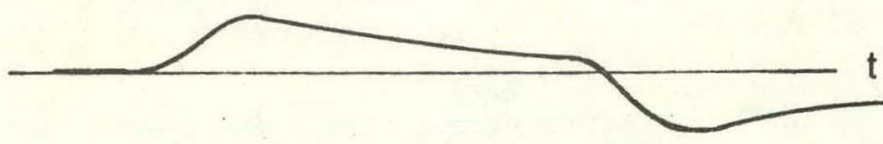

c) Monitor current, if $L / R_{S}$ ratio is high.

Figure 2 - Anticipated monitor waveforms for "square" pulse of beam current. 


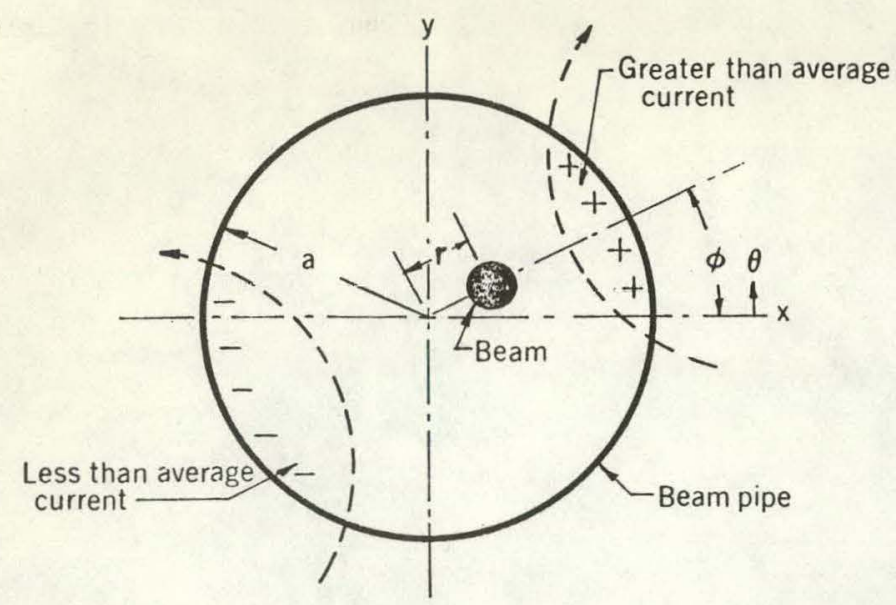

Figure 3 - Illustration showing beam off-center within beam pipe. Dashed lines indicate sense of magnetic field due to change in wall current densities.

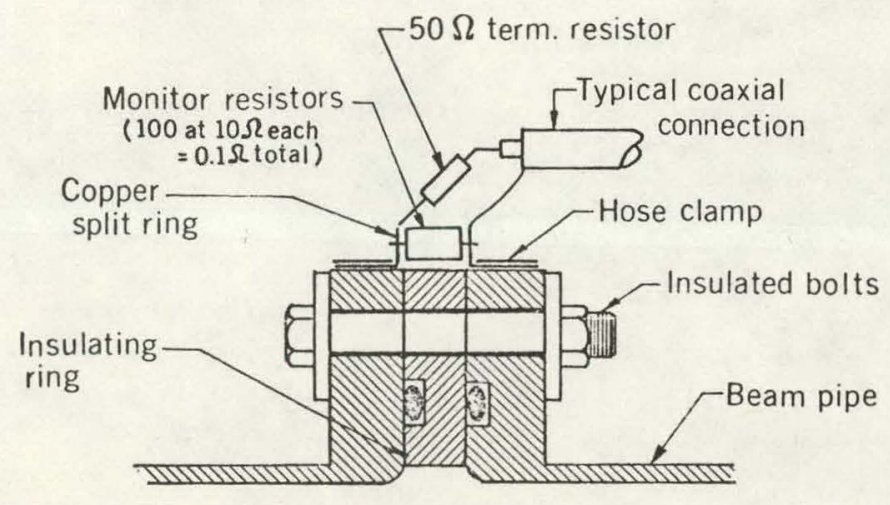

Vacuum

Figure 4 - Typical section through ERA Injector beam munilus.

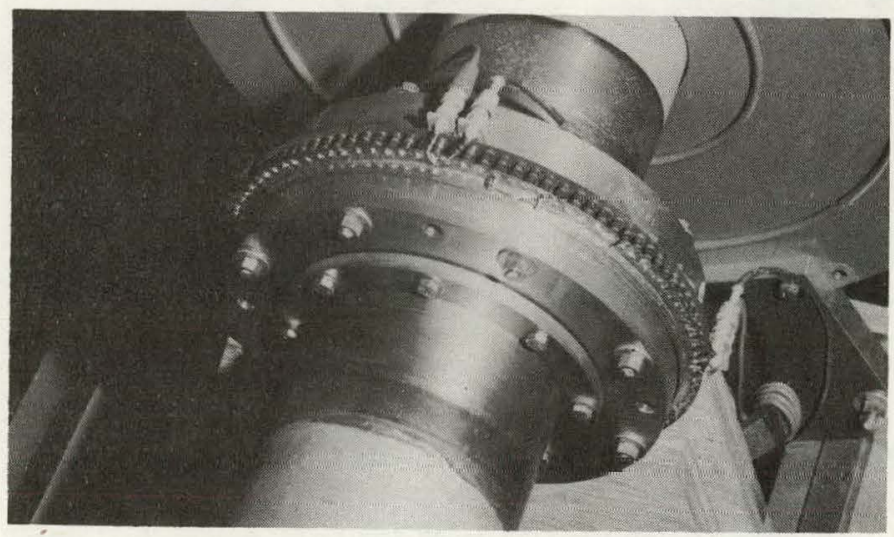

Figure 5 - Photo of installed ERA Injector beam monitor.
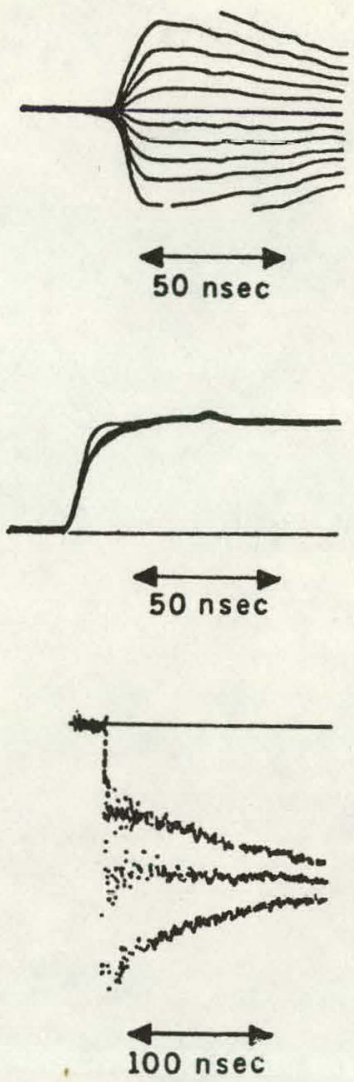

Figure 6 - Calibration waveforms for ERA Injector beam monitor: a) "difference" signal for center conductor at 12 lateral positions $2 \mathrm{~cm}$ apart, with input pulse rise time of $\sim 10 \mathrm{~ns}$; b) superimposed "sum" signals for same conditions; c) signal from one quadrant monitor connection for center conductor at +5 , 0 and $-5 \mathrm{~cm}$ lateral position with input pulse rise time of $\sim 1 \mathrm{~ns}$ which demonstrates rapid response time of munllor.

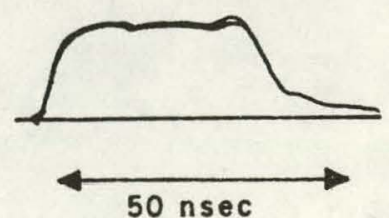

Figure 7 - "Sum" beam current waveform from ERA Inject or beam monitor. 


\section{LEGAL NOTICE}

This report was prepared as an account of work sponsored by the United States Government. Neither the United States nor the United States Atomic Energy Commission, nor any of their employees, nor any of their contractors, subcontractors, or their employees, makes any warranty, express or implied, or assumes any legal liability or responsibility for the accuracy, completeness or usefulness of any information, apparatus, product or process disclosed, or represents that its use would not infringe privately owned rights. 
